\title{
Clínicas do trabalho: filiações, premissas e desafios
}

\author{
Pedro Fernando Bendassolli ${ }^{\mathrm{I}, 1}$ e Lis Andrea Pereira Soboll ${ }^{\mathrm{II}}$ III, 2 \\ ${ }^{\mathrm{I}}$ Universidade Federal do Rio Grande do Norte \\ ${ }^{\text {II }}$ FAE Centro Universitário Franciscano \\ III Universidade Federal do Paraná
}

\begin{abstract}
O trabalho é um objeto de estudo compartilhado por diversas abordagens da psicologia, cada qual orientada por pressupostos epistemológicos, teóricos, metodológicos e deontológicos específicos. Em uma avaliação geral, três grandes ênfases são observadas no domínio da Psicologia Organizacional e do Trabalho (POT): cognitiva, social e, mais recentemente, clínica. Este artigo, de desenho teórico, busca delinear as características das clínicas do trabalho. Analisamos suas principais filiações e origens teóricas, as premissas assumidas e compartilhadas pelas abordagens que as representam, e seus grandes temas de pesquisa e de intervenção. Concluímos com uma proposta de situar as clínicas do trabalho tendo, como referência, uma análise paradigmática mais ampla, a qual considera a coexistência de paradigmas neopositivistas e compreensivos (não positivistas) da POT. Propomos que seu posicionamento próximo aos paradigmas compreensivos pode gerar determinadas tensões e desafios com importantes consequências para a atuação dos psicólogos (clínicos) do trabalho.
\end{abstract}

Palavras-chave: Clínicas do trabalho, Função psicológica do trabalho, Sofrimento no trabalho, Abordagens qualitativas do trabalho.

Work clinics: affiliations, assumptions and challenges

Work is a subject matter that several psychological approaches share, each one driven by specific epistemological, theoretical, methodological and deontological assumptions. Generally speaking, the realm of Organizational and Work Psychology (OWP) involves three main focuses: cognitive, social and, more recently, clinical. This article, of a theoretical nature, attempts to outline the characteristics of work clinics. We analyze their main affiliations and theoretical roots, the assumptions made and shared by their representative approaches, and their main subjects of research and intervention. We conclude with a proposal to locate work clinics using as reference a broader paradigm analysis taking account of coexisting neo-positivist and comprehensive (non-positivist) OWP paradigms. We propose that locating them close to comprehensive paradigms may lead to certain stresses and challenges, with significant consequences for the actions of (clinics) work psychologists.

Keywords: Work clinics, Psychological function of work, Work suffering, Qualitative approaches to work.

\section{Introdução}

Un ma avaliação panorâmica das diversas perspectivas psicológicas que se debruçam sobre o mundo do trabalho na atualidade nos sugere que a unidade está longe de ser alcançada. De fato, diversas são as formas de apropriação psicológica das questões engendradas pelo trabalho, das quais podemos citar, sem sermos exaustivos, a cognitiva, a social e a clínica. Mesmo tendo o trabalho como objeto comum, elas divergem em termos de inscrições paradigmáticas, teóricas, metodológicas e deontológicas. Enquanto a psicologia do trabalho de

1 Psicólogo, Doutor em Psicologia Social pelo Instituto de Psicologia da USP. Pós-Doutor pela Université Paris IX. Professor no Departamento de Psicologia da UFRN.

2 Psicóloga, Doutora em Medicina Preventiva pela Faculdade de Medicina da USP. Professora no Mestrado em Organizações e Desenvolvimento da FAE Centro Universitário Franciscano (Paraná). Professora no Departamento de Psicologia da UFPR. 
inspiração cognitiva está interessada, por exemplo, em apreender como os indivíduos processam as informações que recebem do ambiente de trabalho e da própria atividade em que estão envolvidos, a psicologia social do trabalho busca articular o trabalho a processos sociais mais amplos, como representações sociais, identidade social, estruturas de poder e processos organizativos. Por sua vez, as abordagens clínicas buscam subsidiar ações de indivíduos e coletivos diante das diversas situações de vulnerabilidade no trabalho, sejam elas manifestadas, sejam objetivadas na forma de sofrimento, como também na forma de demandas, de "provas" do real do trabalho contra as quais o sujeito é chamado a se afirmar.

No registro paradigmático, enquanto as psicologias cognitivas do trabalho dependem, em geral, das premissas do neopositivismo, com seu acento sobre a apreensão objetiva dos fenômenos investigados, as psicologias sociais se amparam em uma diversidade maior de fontes, como no marxismo, nas abordagens sócio-históricas, nos interacionismos. Já as perspectivas clínicas têm origens e trajetórias ainda mais matizadas, pois incluem referências à psicanálise, à psicossociologia, à psicologia social clínica, à psicodinâmica do trabalho, à clínica da atividade, à ergonomia e também à filosofia e à antropologia.

O objetivo geral deste artigo é apresentar, sucinta e esquematicamente, as clínicas do trabalho. Não se trata, podemos dizer logo de partida, de uma clínica de divã, focada em problemáticas singulares, girando em torno das fantasmáticas individuais. E também não se trata de uma abordagem que dilui o sujeito em estruturas (em geral, sociais) que o antecedem. A ênfase da palavra clínica nesse caso é sobre a articulação do mundo psíquico com o mundo social. A clínica do trabalho aproxima-se de uma clínica social, cuja pauta de pesquisa e intervenção é a realidade vivenciada pelos sujeitos. Em não sendo uma clínica exclusivamente do sujeito intrapsíquico, incorpora, em seus questionamentos, a produção social do sofrimento no trabalho, bem como a produção de circunstâncias pelas quais o trabalho é reconstruído pela ação coletiva e individual. Quer dizer, não é uma clínica do sofrimento, atenta, exclusivamente, aos aspectos deletérios e nocivos do trabalho; trata-se de uma clínica que, apesar de partir ou pressupor o sofrimento, vai além dele e enfatiza os aspectos criativos e construtivos do sujeito em sua experiência no trabalho.

Em termos específicos, pretendemos identificar neste artigo as filiações teóricas das clínicas do trabalho, as premissas por elas compartilhadas e os grandes temas de pesquisa e de intervenção encontrados nessa abordagem. Buscaremos desenvolver também uma reflexão que situe as clínicas do trabalho em um quadro paradigmático amplo, configurado por dois grandes grupos heterogêneos: de um lado, as abordagens neopositivistas, nas quais podemos situar, grosso modo, as psicologias cognitivas e experimentais do trabalho; de outro, as abordagens não positivistas - as quais incluem paradigmas compreensivos, interpretativos, hermenêuticos e também o clínico. Enquanto o primeiro grupo parece estar mais concernido com questões de previsão e controle no trabalho (desempenho, eficiência, etc.), o segundo volta-se para questões de compreensão, no sentido de um entendimento singular das situações, das vivências e experiências dos sujeitos, visando a uma transformação não necessariamente de cunho econômico-instrumental. Usaremos o recurso à díade controle versus compreensão para elucidar o posicionamento das clínicas do trabalho, especialmente do ponto de vista da atuação dos psicólogos por elas orientados. Por fim, concluímos o artigo com a proposição de algumas tendências e desafios das clínicas de trabalho no Brasil. 


\section{Filiações teóricas}

A atenção ao trabalho com os instrumentais da clínica não são novidade. Podemos dizer que essa perspectiva entrou nos domínios do trabalho pelo eixo da saúde mental - mais especificamente, o da psicopatologia do trabalho, campo originalmente atrelado à psiquiatria. No contexto francês, por exemplo, Sivadon (1957), Veil (1964) e Le Guillant (1984) são os principais precursores.

Sivadon (1957) abordou os problemas de adaptação individual no trabalho. Para ele, as neuroses de trabalho surgiam de desequilíbrios nos processos adaptativos provocados por situações de insegurança e de conflitos. Sua abordagem era centrada nas fragilidades do trabalhador nas mais variadas situações laborais. Veil (1964) amplia essa perspectiva de análise ao integrar tanto uma atenção aos aspectos singulares e psicológicos do sujeito como também à organização do trabalho. Esse autor destaca que o trabalho possui uma polaridade: ao mesmo tempo em que é fonte de desgaste e sofrimento, ele é também atividade criativa e meio de sublimação. Influenciado pela psicanálise, Veil traça a fronteira tênue, no registro do trabalho, entre prazer e sofrimento e descarta a ideia de neurose de trabalho, defendida a priori, voltando-se para a análise situacional das experiências do sujeito no trabalho e para a elucidação, de um ponto de vista fenomenológico, das diversas formas de desadaptação provocadas pela saturação dos mecanismos de defesa.

Le Guillant (1984), contudo, é quem mais parece ter contribuído para a fundação de uma abordagem especificamente clínica do trabalho, insistindo na indivisível união entre o indivíduo e seu meio. Inspirado em tradições do materialismo histórico-dialético, Le Guillant acredita que o psiquismo é um reflexo da realidade material, sendo condicionado pelas normas e condições sociais. $\mathrm{O}$ autor propõe que o analista (clínico) do trabalho tome, como ponto de partida, as situações concretas vivenciadas pelo trabalhador, pois é nelas que ele encontrará as diversas manifestações patológicas. Algumas de suas investigações tornaram-se bem conhecidas, como a hipótese da neurose das telefonistas. Nesse tipo de neurose, Le Guillant havia identificado a inscrição, na estrutura organizativa do trabalho, da fadiga nervosa vivenciada por aquelas profissionais. $\mathrm{O}$ autor propõe então uma análise da fadiga em três planos: no biofisiológico, no psicoafetivo e no psicossocial, tendo, como pano de fundo, o próprio trabalho e as relações objetivas criadas entre o trabalhador e seu mundo laboral.

Assim, Sivadon (1957) e Veil (1964) inauguram uma clínica do sujeito em suas relações com o trabalho, enfatizando as questões de natureza intrapsíquica, ao passo que Le Guillant (1984) abre as vias para uma clínica (social) das situações de trabalho (Lhuilier, 2006a). Nessas duas grandes abordagens podemos localizar os primórdios de uma clínica social do trabalho, sem, contudo, negar a natureza dialética e não raras vezes conflituosa dessas duas dimensões (individual e social). Mas será necessário avaliarmos a confluência de outras abordagens para melhor compreendermos a proposta das clínicas do trabalho. Destas, destacam-se, na sequência, a psicossociologia, a sociopsicanálise, a ergonomia e a psicanálise.

A psicossociologia (também denominada de psicologia social clínica ou sociologia clínica - ver Gaulejac, Hanique \& Roche, 2007) recobre um amplo leque de abordagens, cuja análise completa fugiria do escopo deste artigo. Retemos desse quadro tão somente algumas observações pontuais. A primeira refere-se a uma questão-chave dessa abordagem, a interrogação sobre a dupla constituição do sujeito - de um lado, um sujeito crivado por elementos intrapsíquicos singulares, especialmente de natureza inconsciente; de outro, um sujeito inscrito num universo social (Barus-Michel, 1987; Giust-Desprairies, 2009). A psicossociologia busca, dessa forma, investigar as reciprocidades entre o individual e o coletivo, o psíquico e o social, sendo também essa uma característica importante das abordagens clínicas do trabalho. 
A psicossociologia contribuiu com as clínicas do trabalho de outros modos, além de com essa insistência sobre a dupla constituição, social e psíquica, do sujeito - e a despeito de alguns de seus próprios autores observarem não ser o trabalho um objeto de investigação direto da psicossociologia (por exemplo, Amado \& Enriquez, 1997). Entre tais contribuições, destacamos sua reflexão sobre os processos grupais, dentro e fora de instituições, oferecendo importantes dispositivos de análise da mudança social. Há também uma contribuição em torno de sua definição de organização, a qual inclui elementos técnicos e normativos, como ainda uma dimensão simbólica (cultura) e outra imaginária (representações compartilhadas). O mesmo pode ser dito sobre a contribuição da psicossociologia sobre a compreensão das instituições, definidas como um conjunto de signos e de símbolos, de representações e de regras, produto das práticas das relações humanas. Nessa linha, a psicossociologia gerou subsídios para a compreensão da natureza dos vínculos que os indivíduos estabelecem com as instituições e as organizações, com reflexos na questão do trabalho.

Outra abordagem encontrada no escopo de influências sobre as clínicas do trabalho é a sociopsicanálise desenvolvida por Gérard Mendel. Como no caso anterior, não temos aqui condições de um desenvolvimento extenso da abordagem desse autor, mas é relevante destacar sua contribuição à clínica do trabalho por meio de seu conceito de ato (Mendel, 1998; Lhuilier, 2006a). Para Mendel, toda clínica do social não pode se dispensar de ser uma clínica do real, captado pela mediação do ato, o qual é por ele compreendido como um processo de interatividade entre, de um lado, um sujeito portador de um projeto de ação e, de outro, a realidade material e simbólica implicada nessa ação. Por meio do ato o sujeito é levado a entrar em contato com a dimensão da realidade que lhe é estranha e que impõe resistência a seus desejos e a seu projeto de ação. Enquanto o projeto é um guia prévio ao ato, este se refere ao desconhecido, àquilo que efetivamente ocorre quando o sujeito submete seu projeto à realidade.

Conforme observa Lhuilier (2006a), o ato mendeliano expõe o sujeito ao contato com o real, situação que inevitavelmente compreende o risco de fracasso de seu projeto de ação. E é precisamente nesse ponto, com a introdução da dimensão do real na discussão sobre o ato, que a mesma Lhuilier, uma das principais autoras a delinear a noção de clínicas do trabalho, propõe situarmos este último, já que o trabalho igualmente envolve um confronto do sujeito com o real - entendido como o que resiste à simbolização, o que ultrapassa o pensamento que dele se pode ter ou fazer previamente. Esse mesmo conceito de real será encontrado na psicodinâmica do trabalho de Dejours $(1990,1993,1995)$ e, com ligeiras diferenciações, na clínica da atividade de Clot $(1995,1999)$, duas importantes representantes das clínicas do trabalho - sem deixar de mencionar ainda seus reflexos na abordagem ergológica de Schwartz (1992, 2000).

Além das influências até agora identificadas, é fundamental assinalar a contribuição da ergonomia para o delineamento do conceito de "real" no âmbito das clínicas do trabalho. Embora não possamos fazer aqui senão uma apreciação esquemática, o "real" da ergonomia é definido em contraste com a tarefa. O trabalho real é a atividade efetivamente realizada pelo trabalhador ou pelos coletivos de trabalho, ao passo que a tarefa diz respeito àquilo que foi prévia e normativamente concebido pela administração, que então age como uma instância prescritora (Leplat \& Hoc, 1983). No hiato entre ambos, prescrito e real, vemos a ação do imprevisto, daquilo que resiste e questiona a tentativa de captura total do trabalho em normas e procedimentos instrumentais ou operatórios; da mesma forma, é nesse hiato que vemos emergir a função do sujeito como agente de seu próprio ato no trabalho.

Encerramos essa breve seção registrando mais uma importante influência teórica sobre as clínicas do trabalho: a psicanálise. Embora não esteja presente em todas as abordagens das clínicas do trabalho (a exemplo da clínica da atividade, de Yves Clot), a psicanálise aplicada ao trabalho apresenta diversas contribuições, dentre as quais destaca-se (Lhuilier, 2006c): a questão dos mecanismos de defesa; os processos de vinculação das pessoas às organizações e às 
instituições, via uma compreensão do ideal de eu; as complexas relações entre o desejo e os objetos de investimento escolhidos pelo sujeito na esfera do trabalho. Essa é, claramente, uma lista parcial das valiosas contribuições da psicanálise com as clínicas do trabalho. Essas contribuições são notáveis em algumas teorias, sendo o exemplo mais destacado a psicodinâmica do trabalho (Dejours, 1990, 1996, 1998; Dejours \& Abdoucheli, 1990). Não podemos deixar de mencionar a influência da psicanálise sobre autores e estudos importantes do Tavistock Institute, como, por exemplo, Bion (1975) e, mais próximo ao universo organizacional, Jaques (1951), Enriquez (1972) e Pagès et al. (1979).

Tendo esclarecido as afiliações teóricas das clínicas do trabalho, serão abordadas, a seguir, seus pressupostos fundamentais.

\section{Premissas compartilhadas}

Conforme observa Lhuilier (2006b), as clínicas do trabalho não constituem uma escola de pensamento, tampouco as abordagens nelas agregadas podem ser ditas homogêneas. Mesmo assim, alguns pontos em comum são aí observados, e é com eles que aqui nos ocuparemos.

O primeiro ponto é o interesse pela ação no trabalho. Mais especificamente, como encontramos na clínica da atividade proposta por Clot $(1999,2008)$, o interesse pela extensão do poder de agir dos sujeitos no trabalho. Busca-se criar condições psicossociais para que os sujeitos se apropriem de sua atividade, seja na forma de um retorno reflexivo sobre ela (pensar sobre), seja na forma de ações conjuntas elaboradas pelos coletivos de trabalho, as quais buscam enfrentar as questões ou dificuldades colocadas pelas atividades comuns.

Ao dizermos que um dos focos das clínicas do trabalho é o poder de agir dos sujeitos e dos coletivos de trabalho, precisamos entender o que está implicado na ideia de poder nesse caso. Na verdade, muitas são as representações sobre o poder, podendo se referir a classes sociais, à posse sobre recursos escassos, à capacidade de influência, à autoridade. Mas o poder de que se trata aqui refere-se ao poder encontrado no nível do ato, no sentido mendeliano visto anteriormente. Clot (2008) acrescenta que o poder, nesse registro, possui alguns endereçamentos: há o poder sobre si mesmo, no sentido do poder do uso de si (Schwartz, 1992); o poder sobre a atividade (a maestria sobre meios-fins); e o poder sobre a atividade dos outros. Há ainda o poder sobre as resistências do real (Lhuilier, 2006a), quando o sujeito consegue enfrentar, criativamente, as restrições, as frustrações e a indeterminação da realidade material implicada em toda forma de atividade.

Um segundo ponto de compartilhamento é o entendimento sobre o trabalho. Nas clínicas do trabalho, esse último não é restrito à sua institucionalização econômica, ao emprego. Ele é apreendido como atividade sustentada por um projeto de transformação do real e de construção de significados pessoais e sociais (Clot, 1999, 2001; Lhuilier, 2006a, 2006b, 2006c). Trata-se de atividade desinteressada, pois, mediante o trabalho, o sujeito enreda-se em uma narrativa coletiva, sai de si mesmo (Clot, 1999; Clot \& Litim, 2006), tomando parte de uma rede na qual é reconhecido e para a qual contribui. Na perspectiva de Clot $(1999,2008)$, o trabalho-atividade envolve uma atenção a si mesmo, à atividade dos outros (no contexto de um gênero profissional coletivo, com suas normas, histórias, regras) e à atividade propriamente dita, ou seja, àquilo que está sendo feito, o que levanta a questão da eficiência, do propósito, até mesmo da estética e do gosto.

Adicionalmente, na concepção das clínicas do trabalho, este é considerado como uma prova inscrita numa práxis, numa demanda pela transformação da realidade (Lhuilier, 2006a). Dizer que o trabalho é uma prova implica no tratamento da dimensão do real. $\mathrm{O}$ trabalho não 
se reduz a um conjunto de representações mentais, sejam individuais, sejam sociais. O conhecimento que se tem do trabalho é também de natureza prática, uma métis (Detienne \& Vernant, 1993), ou, como observa Dejours (1993), uma inteligência prática. O corpo do trabalhador está engendrado no confronto com o real e com suas resistências. Nas clínicas do trabalho o saber construído sobre o trabalho é inseparável da experiência donde ele emerge, bem como dos efeitos que ele produz (Lhuilier, 2006c). Os discursos ou o significado do trabalho não podem ser apartados do ato; portanto, não devem ser produções extemporâneas em relação às atividades dos coletivos de trabalho ou de um sujeito implicado em sua atividade. As clínicas do trabalho questionam as tentativas de racionalização do trabalho, as quais, segundo Lhuilier (2006a, 2006b), têm como efeito a ocultação do trabalho, no sentido de um apagamento da dimensão real nele envolvida, à parte suas dimensões simbólicas (cultura) e imaginárias (representações). Quer dizer, busca-se, nas clínicas do trabalho, restituir a este último sua dimensão ontológica-chave: a de confronto do homem com a natureza, consigo mesmo e com os outros.

O terceiro ponto de convergência é a defesa de uma teoria do sujeito. Há uma crítica explícita à concepção de sujeito encontrada em diversas abordagens das psicologias cognitivas (e experimentais) do trabalho, para as quais o sujeito é equiparado muitas vezes a uma máquina que capta informações de seu ambiente, as processa e as devolve a esse mesmo ambiente na forma de comportamento (no sentido behaviorista clássico). Nas clínicas do trabalho, o sujeito é alvo de teorizações mais matizadas. Por exemplo, na psicodinâmica do trabalho trata-se de um sujeito dividido por conflitos intrapsíquicos, mas que também não pode se constituir fora da relação ao outro, em jogos de reconhecimento pelos quais o sofrimento nas atividades de trabalho é transformado em prazer e também contra o qual o sujeito afirma seus desejos (Dejours \& Molinier, 1989). Já na clínica da atividade o sujeito é atravessado por forças sóciohistóricas, por gêneros discursivos, no contexto dos quais ele faz uma apropriação subjetivizante (singularizante e personalizante). Por meio da atividade, no seu confronto com o real, o sujeito se desenvolve e se afirma (Clot, 1998).

Um quarto ponto de convergência pode ser expresso pela pergunta: quais os propósitos de uma clínica do trabalho? Com o que exatamente ela busca contribuir? Para responder a essas perguntas é importante a discussão sobre o lugar reservado pela perspectiva clínica ao sofrimento no trabalho. Pode-se dizer que um primeiro foco de preocupação das clínicas do trabalho é a vulnerabilização do sujeito e dos coletivos profissionais. Um sinal importante dessa vulnerabilidade é o processo de individualização e o desmantelamento dos coletivos de trabalho e a consequente perda de referenciais compartilhados. Outro sinal, que retomaremos mais à frente neste artigo, são as diversas modalidades de manifestação do malestar no trabalho, incluindo doenças físicas, transtornos e alterações mentais e psicossociais.

A emergência do sofrimento no trabalho é um forte motivo de convocação das clínicas do trabalho (Lhuilier, 2006c). Busca-se questionar o sofrimento numa dupla perspectiva: de suas inscrições ou produções sociais, como nos modos de organização e divisão do trabalho, e também na perspectiva dos processos psíquicos que operam nos indivíduos como resposta ao sofrimento, seja em termos da falência ou falhas nas defesas psíquicas (Dejours, 1990), seja de bloqueios ou impedimentos do poder de agir (Clot, 2008). Como se vê, há uma tentativa de não reduzir o sofrimento à dimensão exclusivamente individual. Em vez disso, o olhar do investigador se volta para o sofrimento que depende de fatores sociais e para sua ressonância com as questões envolvendo a subjetividade ou a vida psíquica. Essa forma de abordar o sofrimento está associada a uma concepção sobre o próprio trabalho como terreno privilegiado de mediação entre economia psíquica e campo social, entre ordem singular e ordem coletiva. Qualquer redução a um ou outro desses polos caracterizaria, do ponto de vista das clínicas do trabalho, uma limitação à análise e à intervenção. 
Embora as situações de sofrimento se apresentem como uma questão fundamental nas clínicas do trabalho, isso não significa que seus domínios se restrinjam aos aspectos deletérios ou alienantes do trabalho. Há mais no trabalho do que simplesmente sofrimento, da mesma forma que o sujeito não se define apenas pelo pathos, mas também por sua capacidade de criação, reinvenção, emancipação e superação das dificuldades colocadas pelo real. $O$ domínio da psicologia clínica do trabalho não é somente o da psicopatologia, tampouco o da psicanálise (no sentido de uma clínica do sujeito psíquico "apartado" do sujeito social). Abrem-se aqui algumas vias interessantes para se pensar a relação sujeito-trabalho. Por exemplo, como dispositivo pelo qual o sujeito institui novas normas, não se fixando àquilo que já está dado (Canguilhem, 1966); como um dispositivo pelo qual o sujeito pode exercitar sua capacidade criadora (Winnicott, 1979/1983); ou ainda como meio de construção da identidade e da vivência de prazer decorrentes do reconhecimento e da mobilização subjetiva (Dejours, 2000).

Na clínica da atividade (Clot, 1999, 2008) há outra ilustração interessante dessa dimensão constitutiva, positiva, do trabalho. Nela, este é entendido como um conjunto de provas, e não como algo a propiciar restrições e fatores inexoravelmente patogênicos. Tais provas são originárias do real da atividade e das relações com outras pessoas que nela intervêm, para não mencionar sua origem no interior do próprio sujeito, marcado por seus projetos, aspirações e pré-ocupações. Essas três fontes geram demandas muitas vezes contraditórias, cabendo aos sujeitos torná-las compatíveis entre si. Ao fazê-lo, sobretudo quando, para isso, intervém a ação dos coletivos de trabalho (denominados por Clot de gêneros profissionais), os sujeitos conseguem afirmar seu poder de agir. O sofrimento surge da atividade impedida, do desenvolvimento bloqueado (Clot, 2001).

Estando já destacados alguns pontos comuns das clínicas do trabalho, é central abordar os temas de relevância de pesquisas e de intervenção nesse enfoque.

\section{Temas de pesquisa e de intervenção}

Embora as questões envolvendo o sofrimento no trabalho não representem todo o domínio de temas das clínicas do trabalho, não há dúvida de que é nesse terreno que elas deixam uma contribuição destacada. Formas de desmontagem do trabalho (Boltanski \& Chiapello, 1999) seguidas, em geral, de fraturas nos processos subjetivadores a ele associados, são ocasiões de sua intervenção. $O$ mesmo pode ser dito com respeito às diversas formas de dessimbolização do trabalho, quando este deixa de ser um objeto investido de significado e passa a favorecer processos de desengajamento afetivo dos sujeitos. Clot $(1998,1999)$ denomina esse processo de des-obramento na situação de trabalho - isto é, o sujeito busca reconhecer e ser reconhecido em gêneros coletivos, nos quais ele contribui com a inscrição de suas obras; quando essa possibilidade é impedida, o trabalho deixa de ser associado à produção de obras e significados e se torna puro domínio de regras exteriormente estabelecidas (trabalho prescrito).

Portanto, um importante tema de pesquisa e intervenção das clínicas do trabalho são as diversas formas de malestar nesse campo. Especificamente, três grupos são identificados na literatura da área (Lhuilier, 2006a, 2006c), os quais têm, em sua gênese, o crescente nível de exigências e demandas colocadas pelas organizações de trabalho aos indivíduos e a redução (ou manutenção em níveis baixos) dos recursos pessoais e coletivos para seu enfrentamento. Diante dessa discrepância fundamental os sujeitos são expostos a situações que enfraquecem seu poder de agir, sua capacidade de enfrentamento e de significação de sua própria experiência. Vejamos cada um dos grupos. 
O primeiro grupo de patologias envolve as patologias da atividade. Especificamente, encontramos aqui as diversas famílias de transtornos músculos-esqueléticos, como também o estresse, a fadiga e as formas brandas ou graves de dissociações psicológicas. $\mathrm{O}$ aspecto mais preocupante, nesse grupo, diz respeito ao bloqueio da atividade e, portanto, dos processos de subjetivação/personalização a elas associados. Um exemplo nesse sentido é a divisão taylorista entre concepção e execução - ainda presente em diversas formas de trabalho na atualidade. Nessa situação, o sujeito é impedido de exercer o controle sobre sua atividade. Como dizia Wallon (1976), ao amputar o homem de sua iniciativa no trabalho amputa-se, ao mesmo tempo, grande parte de suas possibilidades como agente. O sujeito é dissociado de seu próprio gesto/ato no trabalho. Distantes mais de cem anos da origem da Administração Científica, ainda continuamos a presenciar formas de dissociação no trabalho, como no exemplo recente dos infoproletários (Antunes, 2009).

O segundo grupo reúne as patologias da solidão e da indeterminação no trabalho. A solidão ocorre devido à fragilização dos ofícios como coletividades articuladas em torno de regras, normas, atividades e identidades comuns. Evidência nesse sentido são as diversas modalidades de gestão dos recursos humanos, como a remuneração variável por desempenho individual, o coaching e a gestão personalizada das carreiras. Já a indeterminação no trabalho tem a ver com a dificuldade dos trabalhadores em compreender os meios e os fins de suas atividades, comprometendo seu processo de apropriação subjetiva. Um exemplo pode ser encontrado no setor de serviços, quando a essência do trabalho se reduz a relações interpessoais com clientes, cujas demandas e exigências de valor nem sempre são claramente compreendidas ou tangíveis. Nesses contextos, há uma rarefação dos critérios de como realizar e conduzir o trabalho, fato a intensificar as exigências endereçadas aos trabalhadores.

O terceiro grande grupo de patologias associa-se aos maus-tratos e à violência no trabalho. Pensa-se aqui nas diversas formas de assédio moral como também na exposição dos indivíduos a situações humilhantes ou ofensivas com as quais nem sempre conseguem lidar. $\mathrm{O}$ sofrimento psíquico surge quando, nessas circunstâncias, os indivíduos são entregues a si próprios e a seus (únicos) recursos pessoais, pois a falta de mediação coletiva permite que o trabalho se transforme num campo de afrontamento no qual, serializados, os indivíduos lutam em situação de grande assimetria de poder com a organização. Da mesma forma, encontramos focos de sofrimento nos diversos processos de rupturas das trajetórias profissionais, como em situações de desemprego, mas também nas transições patrocinadas por uma dinâmica organizacional acelerada e aparentemente indiferente ao impacto das mudanças sobre as biografias profissionais.

Na próxima seção discutiremos de que modo as clínicas do trabalho se propõem a pesquisar e a intervir nesses três grandes grupos de sofrimento no trabalho. Ao fazê-lo, elas buscam se diferenciar de outras abordagens presentes no campo da psicologia organizacional e do trabalho (POT), especialmente das abordagens cognitivo-comportamentais (com sua ênfase no estresse), e até mesmo de outras abordagens clínicas que se pautam por uma psicologização do social - como quando propõem uma causalidade que localiza no interior do sujeito as origens do sofrimento no trabalho.

\section{Posicionamento epistemológico no campo da POT}

Nesta seção nosso propósito é analisar, considerando um quadro paradigmático amplo, qual o posicionamento das clínicas do trabalho em relação ao de outras abordagens presentes no campo da psicologia organizacional e do trabalho (POT), e quais consequências isso pode trazer para a atuação do psicólogo. Para tanto, propomos, sem a pretensão de esgotar o tema, 
uma divisão entre duas grandes influências paradigmáticas nesse campo: os paradigmas neopositivistas, de um lado, e os paradigmas não-positivistas ou compreensivos, de outro. Enquanto os primeiros orientam suas abordagens no sentido de focar na previsão e controle, os segundos o fazem no sentido da compreensão dos fenômenos presentes no mundo do trabalho.

A díade compreensão versus controle possui longa história no pensamento científico moderno. Em linhas bem amplas e de forma esquemática, podemos dizer que o positivismo (ou sua variante mais recente, o neopositivismo - ver Guba, 1990), baseado em uma concepção de ciência como ponto de acesso à "verdadeira realidade", além de estabelecer uma epistemologia realista, também fusionou uma ética da verdade e uma ética do bem. Desse modo, a ética positivista passa a ser "objetiva" e "cientificamente fundada" (Rorty, 1982). Em contrapartida, Dilthey (1911/1992) propôs a defesa de um método próprio às ciências do espírito: a hermenêutica. Nesse caso, o propósito do empreendimento das ciências humanas e sociais era compreender o significado.

Tal confronto perpassou o tempo e assumiu distintas feições, como entre metodologias qualitativa e quantitativa, ciência pura e ciência aplicada (por exemplo, psicologia aplicada), orientações nomotéticas e orientações idiográficas, objetivo e subjetivo. A psicologia, naturalmente, herdou essas dicotomias, e um dos tantos sinais nessa direção é o fato de ela ser ora classificada entre as ciências biológicas, ora entre as humanas. Quando próxima do polo da compreensão, mais se nota na psicologia uma preocupação em "entender" o singular (na tradição da Verstehen, de Weber, 1922/2001). A compreensão não visa, necessariamente, o estabelecimento de leis ou a identificação de regularidades, mas a descrição de razões (não de causas) para os fenômenos estudados. Por sua vez, o controle está associado a uma metodologia "robusta" voltada à explicação e, como consequência, à previsão e ao controle dos fenômenos. No primeiro caso, recorre-se à intencionalidade do sujeito, ao discurso e a categorias fenomenológicas (por exemplo, a consciência); no segundo, recorre-se à probabilidade (estatística).

Pensando especificamente no caso das clínicas do trabalho, elas, por suas próprias características, estão muito mais próximas do polo da compreensão que do controle. Porém, quando dividem o mesmo espaço com as abordagens positivistas (ou neopositivistas), e sobretudo quando dividem com estas um mesmo objeto, o trabalho (especialmente em organizações), podem dar ensejo à emergência de tensões importantes, as quais têm um impacto sobre a ação dos psicólogos ou profissionais por elas orientados.

Para entendermos tais tensões, precisamos colocar a própria POT em perspectiva: trata-se de uma área historicamente ligada à "psicologia aplicada", a qual possui uma forte vocação interventiva, certamente inspirada no ideário neopositivista de que "uma boa teoria é uma boa prática". De fato, nesse paradigma formou-se a conviç̧ão de que a ciência pode transformar a realidade e de que essa ação é ética e moralmente justificada, desde que lastreada por uma epistemologia e métodos realistas. No campo das organizações capitalistas, a inserção da POT, via quantificação, implicou na oferta de soluções cientificamente embasadas destinadas ao controle do comportamento. Não é sem razão que Taylor associou à sua teoria de administração o rótulo de científica. Assim, no eixo temático das abordagens neopositivistas, o interesse primário é pelo comportamento, o qual é explicado com vistas ao manejo do desempenho, uma unidade temática fundamental da POT neopositivista.

A tensão aqui tem a ver justamente com a definição de desempenho. Desde a proposta dos tempos e movimentos até as sofisticadas técnicas multimétodos e multiníveis da atualidade (Klein \& Kozlowski, 2000), o desempenho continua sendo um tema tortuoso. E parte da razão disso pode ser atribuída aos paradigmas não-positivistas da POT, nos quais situamos as clínicas do trabalho. Veja-se, por exemplo, a tese de Dejours (2003) de que a avaliação de desempenho é problemática porque o próprio trabalho é um enigma. $O$ autor baseia-se na tradição da ergonomia francesa, a qual opera uma distinção entre trabalho prescrito e trabalho real - o que 
de fato acontece no trabalho, seja na forma de reelaboração positiva da tarefa planejada a priori, seja na forma de erro. O desencaixe entre ambos implica em problemas de desempenho, aqui compreendido como conjunto de ações que geram um resultado de valor econômico, ou então problemas de saúde - compreendida no amplo sentido de processos psicossociais de bem-estar (e não meramente como a ausência de sofrimento ou de sintomas psicopatológicos). A tensão se materializa na observação de que nem sempre é possível aliar desempenho e saúde. Mais amplamente falando, nem sempre é possível conciliar os interesses das organizações capitalistas e os interesses de seus membros.

As tensões não se encerram aqui. Consideremos outro exemplo, em particular a tensão em torno da interpretação da demanda e da intervenção. Em geral, o que se espera de um psicólogo organizacional em organizações capitalistas é que este ofereça instrumentos de controle à gestão. Isso pode vir na forma de tecnologias como também na de pesquisas aplicadas. Ao avançar rumo ao polo da compreensão, a intervenção do psicólogo POT pode assumir outras configurações, não necessariamente envolvidas diretamente com a adaptação do sujeito aos imperativos do desempenho e da eficiência. Daí que uma configuração importante dessas clínicas é a pesquisa-ação, a qual pressupõe um tipo de envolvimento do psicólogo ou profissional de POT que vai além do uso de procedimentos exclusivamente técnicos. Ele atua como um co-agente no nível dos processos organizativos, especialmente os micro-organizativos.

Conforme destaca Lhuilier (2006a, 2006c), o modelo da pesquisa-ação é o que melhor se ajusta à proposta das clínicas do trabalho, pois, em primeiro lugar, tais clínicas dão um valor heurístico elevado ao real nas situações de trabalho, não se fixando apenas no simbólico (teorias existentes) ou no imaginário (representações compartilhadas). Nesse sentido, o psicólogo assume duas posturas. Uma, a de clínico social, interessado na transformação efetiva do trabalho, seja no sentido de se esforçar pela redução dos elementos que geram sofrimento (como a organização prescrita do trabalho), seja no dos elementos que bloqueiam ou reduzem o poder de agir dos sujeitos. A outra postura é a de pesquisador-clínico, quando se espera dele uma postura engajada, capaz de questionar o próprio conhecimento produzido e os usos que dele podem vir a ser feitos pelos coletivos de trabalho. Aqui se trata de uma pesquisa vista como práxis social.

A aproximação das clínicas do trabalho dos paradigmas compreensivos determina também importantes questões deontológicas. Qual o papel do psicólogo POT nesse caso? Seria o de promover a conscientização e o empoderamento dos sujeitos sobre o trabalho ou então o de incrementar sua performance, seu rendimento, sua adaptação às regras do trabalho prescrito e da organização do trabalho?

Os proponentes das clínicas do trabalho (por exemplo, Lhuilier, 2006a) são muito claros no sentido de demarcar seu posicionamento ético: o que se busca é o aumento do poder de agir dos sujeitos, uma coprodução de conhecimento-ação vinculado às situações reais e às vivências dos sujeitos. Desse modo, são privilegiadas metodologias qualitativas, métodos nos quais os próprios sujeitos são convocados a refletir sobre suas práticas. Inovações importantes foram desenvolvidas para atender à necessidade de técnicas mais sensíveis às problemáticas investigadas, tais como a técnica da auto-confrontação cruzada (Clot, 2005) ou dos grupos de análise das práticas (Dejours, 1996, 1998). Nessas técnicas são destacados, em primeiro plano, dispositivos interpretativos que permitam o aumento da reflexividade dos sujeitos sobre suas atividades, a compreensão das defesas utilizadas para fazer face às dificuldades, às angústias e ao sofrimento, bem como a apropriação de estratégias bem-sucedidas e criativas.

A vinculação a paradigmas não-positivistas é transparentemente assumida pelas clínicas do trabalho. Além disso, elas não elegem como seu ambiente exclusivo de atuação as organizações capitalistas. Como vimos neste artigo, elas entendem que há mais no trabalho do que simplesmente a relação contratual e instituída do emprego. $\mathrm{O}$ trabalho é atividade pela qual o sujeito se afirma na sua relação consigo mesmo, com os outros com quem ele trabalha e 
pela qual colabora para a perpetuação de um gênero coletivo. Não é à toa que encontramos a utilização das clínicas do trabalho em contextos não tradicionais, como em hospitais, presídios, instituições de polícia e escolas. Sua extensão a esses ambientes nos permite captar outra premissa assumida e compartilhada pelas clínicas do trabalho: a necessidade de lutar contra a vulnerabilização social, contra a ocultação do trabalho (ou, mais especificamente, do real do trabalho) e as formas de alienação e invisibilidade social.

\section{Conclusões}

Apesar de não serem uma nova escola nem um campo homogêneo, as clínicas do trabalho oferecem contribuições valiosas para a análise deste na contemporaneidade. Distanciam-se de certa representação individualista da clínica, que elege como seu foco primário de atenção os processos intrapsíquicos, minimizando ou simplesmente ignorando as ramificações sociais do sujeito. Em contrapartida, buscam se posicionar como clínicas sociais do trabalho, pois se equilibram no fino e tênue limite entre psíquico e social, vendo entre eles jogos complexos de reciprocidade e tensão.

Entre seus traços fundamentais, as clínicas do trabalho defendem a centralidade psíquica e social deste último, vendo o trabalho como uma atividade material e simbólica constitutiva do laço social e da vida subjetiva. Elas atribuem grande importância às situações concretas de trabalho, valorizando um questionamento sobre as demandas colocadas pelo mundo do trabalho aos psicólogos e também sobre o uso dos dispositivos propostos quando da análise, pesquisa e intervenção naquelas situações. Partilham a convicção de que as práticas de pesquisa devem ser engajadas, e não simples expedientes de coleta de dados, muitas vezes sem a devida ressonância no trabalho realizado pelas pessoas. Atentas ao traumático no trabalho, suas investigações se destinam a compreender as origens e as manifestações do sofrimento, como também a compreender e subsidiar os processos de resistência e de superação por parte dos coletivos de trabalho.

Apesar de sua promissora contribuição, Lhuilier (2006a) observa que as clínicas do trabalho são frequentemente pouco lembradas nos manuais da área, na França. No Brasil, a situação parece se repetir, embora seja necessária uma análise cautelosa nesse ponto. De um lado, há, sob a produção local, uma grande influência da literatura e dos modismos estrangeiros, especialmente norte-americanos. De fato, os EUA são os grandes produtores e exportadores de tecnologias gerenciais voltadas ao incremento da performance e da eficiência no trabalho, além de terem sido o berço das versões "industriais" da psicologia, caracterizadas por sua aliança ao neopositivismo e, consequentemente, à metodologia experimental, quase-experimental e correlacional. Sob a influência dessas fontes, o sofrimento no trabalho é às vezes reduzido à versão do estresse.

De outro lado, há também no Brasil tradições de pesquisa e intervenção no trabalho já consolidadas e que se configuram a partir de outras influências, especialmente da tradição francesa de análise do trabalho - como a psicossociologia (Araújo \& Carreteiro, 2001; Freitas \& Motta, 2000), a ergologia (Athayde \& Brito, 2007), a ergonomia (Sznelwar \& Mascia, 2007), a psicopatologia (Lima, 2006), a psicodinâmica do trabalho (Lancman \& Sznelwar, 2008; Merlo \& Mendes, 2009) e, mais recentemente, a clínica da atividade (Botechia \& Athayde, 2008; Lima, 2007; Osorio da Silva, 2007). Não podemos deixar de mencionar também as abordagens que se aproximam das ciências que estudam mais diretamente a saúde do trabalhador, seja em uma perspectiva epidemiológica (Codo et al., 2004) ou baseada nas práticas e nos processos de construção de sentidos (Sato et al., 2008). Comparado ao primeiro, este lado do campo apresenta uma complexidade maior no sentido de filiações paradigmáticas, 
formas de engajamento, postura do psicólogo e, notadamente, áreas de atuação. Um ponto que talvez seja comum entre essas abordagens é seu reconhecimento de que o sofrimento no trabalho, além de possuir várias formas de manifestação, enraíza-se em questões de cunho social, econômico e cultural amplos. Daí encontrarmos uma forte aproximação com as clínicas do trabalho descritas neste artigo.

Para finalizar, vemos que há grandes expectativas para a ampliação e afirmação das perspectivas abertas pelas clínicas do trabalho no contexto brasileiro. Entre as tendências, podemos destacar a ampliação ainda maior de grupos de pesquisas em clínicas do trabalho e a crescente diversificação de públicos investigados, os quais não se limitam, como vimos, ao enquadre das organizações formais de trabalho, mas envolvem setores marginalizados ou ocultados. Já como desafios, coloca-se, a nosso ver, o manejo das tensões apontadas neste artigo, referentes ao confronto observado entre os distintos posicionamentos epistemológicos no campo, presente desde a formação nos cursos de graduação. Somando-se a este, há uma necessidade de formulação de políticas públicas, tanto voltadas ao trabalho como à saúde, que contemplem uma visão não individualizante e que considerem os processos de subjetivação e de sofrimento relacionados ao trabalho.

\section{Referências}

Amado, G. \& Enriquez, E. (1997). Psychodynamique du travail et psychosociologie. Revue Internationale de Psychosociologie, 3 (6-7), 157-167.

Antunes, R. (Org.). (2009). Infoproletários. São Paulo: Boitempo.

Araujo, J. N. G. \& Carreteiro, T. C. (2001). Cenários sociais e abordagem clínica. São Paulo: Escuta.

Athayde, M. \& Brito, J. (2007). Apresentação. In Y. Schwartz \& L. Durrive (Orgs.), Trabalho e ergologia (pp. 5-9). Niterói: EDUFF.

Barus-Michel, J. (1987). Le sujet social. Paris: Dunod.

Bion, W. R. (1975). Experience in groups. Londres: Ballantine.

Boltanski, L. \& Chiapello, E. (1999). Le nouvel esprit du capitalisme. Paris: Gallimard.

Botechia, F. \& Athayde, M. (2008). Conversas sobre o trabalho sob o ponto de vista da atividade. In M. E. B. Barros \& A. L. Margoto (Orgs.), Trabalho e saúde do professor (pp. 43-78). Belo Horizonte: Autêntica.

Canguilhem, G. (1966). Le normal et le pathologique. Paris: PUF.

Clot, Y. \& Litim, M. (2006). Sens du travail. In J. Allouche (Org.), Encyclopédie des ressources humaines (pp. 1391. 1401). Paris: Vuibert.

Clot, Y. (1995). Le travail sans l'homme? Paris: La Découverte.

Clot, Y. (1998). Le sujet au travail. In J. Kergoat (Org.), Le monde do travail (pp. 165-171). Paris: La Découverte.

Clot, Y. (1999). La fonction psychologique du travail. Paris: PUF.

Clot, Y. (2001). Clinique du travail, clinique du réel. Journal des psychologues, 185, 48-51.

Clot, Y. (2005). L'autoconfrotation croisée en analyse du travail. In L. Filliettaz \& J. P. Bronckart (Orgs.), L'analyse des actions et des discours en situation de travail (pp. 37-55). Louvain-la-Neuve: Peeters.

Clot, Y. (2008). Travail et pouvoir d'agir. Paris: PUF.

Codo, W., Menezes, I. V., Tavares, M., Lima, M. E. A. \& Diniz, G. (2004). O Trabalho enlouquece? Petrópolis: Vozes.

Dejours, C. \& Abdoucheli, E. (1990). Itinéraire théorique en psychopathologie du travail. Prévenir, 20, 127-150.

Dejours, C. \& Molinier, P. (1989). De la peine au travail. Autrement (Série mutations), 142, 138-151.

Dejours, C. (1990). Travail et usure mentale. Paris: Bayard. 
Dejours, C. (1993). Intelligence pratique et sagesse pratique: deux dimensions méconnues du travail réel. Éducation Permanente, 116, 47-70.

Dejours, C. (1995). Le facteur humain. Paris: PUF.

Dejours, C. (1996). Psychologie clinique et tradition comprehensive. In Y. Clot (Org.), Les histories de la psychologie du travail (pp. 197-182). Toulouse: Octarès.

Dejours, C. (1998). Soufrance en France. Paris: Le Seuil.

Dejours, C. (2003). L'évaluation du travail à l'épreuve du reel. Paris: INRA.

Detienne, M. \& Vernant, J. P. (1993). Les ruses de l'intelligence: la mètis des grecs. Paris: Flammarion.

Dilthey, W. (1992). Teorias das concepções do mundo. Lisboa: Edições 70. (Original publicado em 1911)

Enriquez, E. (1972). Imaginaire social, refoulement et répression dans les organisations. Connexions, 3, 65-93.

Freitas, M. E. \& Motta, F. C. P. (2000). Vida psíquica e organização. Rio de Janeiro: FGV.

Gaulejac, V., Hanique, F. \& Roche, P. (2007). La sociologie clinique. Toulouse: Érès.

Giust-Desprairies, F. (Org.). (2009). Entre social et psychique. Paris: L'Harmattan

Guba, E. G. (1990). The paradigm dialog. Londres: Sage.

Jaques, E. (1951). The changing culture of a factory. Londres: Tavistock.

Klein, K. J. \& Kozlowski, S. W. J. (Eds.). (2000). Multilevel theory, research, and methods in organizations. San Francisco: Jossey-Bass.

Lancman, S. \& Sznelwar, L. (2008). Christophe Dejours: da psicopatologia a psicodinamica do trabalho. Rio de Janeiro: Fiocruz.

Le Guillant, L. (1984). Quelle psychiatrie pour notre temps. Toulouse: Érès.

Leplat, J. \& Hoc, J. M. (1983). Tâche et activité dans l'analyse psychologique des situations. Cahiers de Psychologie Cognitive, 3 (1), 49-63.

Lhuilier, D. (2006a). Cliniques du travail. Toulouse: Érès.

Lhuilier, D. (2006b). Cliniques du travail. Nouvelle Revue de Psychosociologie, 1, 179-193.

Lhuilier, D. (2006c). Cliniques du travail: enjeux et pratiques. Pratiques Psychologiques, 12, 205-219.

Lhuilier, D. (2009). Travail, management et santé psychique. Connexions, 91, 85-101.

Lima, M. E. A. (2007). Contribuições da clínica da atividade para a segurança no trabalho. Revista Brasileira de Saúde Ocupacional, 32, 99-108.

Lima, M. E. A. (Org.). (2006). Escritos de Louis Le Guillant. Petrópolis: Vozes.

Mendel, G. (1998). L'acte est une aventure. Paris: La Découverte.

Merlo, A. R. C. \& Mendes, A. M. (2009). Perspectivas do uso da psicodinâmica do trabalho no Brasil. Cadernos de Psicologia Social do Trabalho, 12 (2), 141-156.

Osório da Silva, C. (2007). As ações de saúde do trabalhador como dispositivo de intervenção nas relações de trabalho. In E. N. Rosa, H. A. Novo, M. E. Barros de Barros \& M. I. Moreira (Orgs.), Psicologia e saúde (pp. 75-90). Vitória: EDUFES.

Pagès, M., Gaulejac, V., Descendre, D. \& Bonetti, M. (1979). L'emprise de l'organisation. Paris: Desclée de Brouwer.

Roger, J. C. (2007). Refaire son métier. Toulouse: Érès.

Rorty, R. (1982). Consequences of pragmatism. Minnesota: University of Minnesota Press.

Sato, L., Lacaz, F. A. C. \& Bernardo, M. H. (2008). Psicologia e saúde do trabalhador: práticas e investigações na saúde pública de São Paulo. In W. C. Campos \& E. B. Silva (Orgs.), Trabalho e saúde (pp. 151-172). São Paulo: DIESAT.

Schwartz, Y. (1992). Travail et philosophie. Toulouse: Octarès.

Schwartz, Y. (2000). Le paradigme ergologique ou un métier de philosophe. Toulouse: Octarès.

Sivadon, P. (1957). Psychiatrie du travail. In H. Desaille (Org.), Cours de médicine du travail (pp. 405-420). Paris: Le François.

Sznelwar, L. I. \& Mascia, F. (Orgs.). (2007). Trabalho, tecnologia e organização. São Paulo: Blucher. 
Veil, C. (1964). Hygiène mentale du travail. Paris: Le François.

Wallon, H. (1976). Lecture d'H. Wallon: choix de textes. Paris: Éditions Sociales.

Weber, M. (2001). Ensayos sobre metodologia sociológica. Bueno Aires: Amorrortu. (Original publicado em 1922)

Winnicott, D. W. (1983). O ambiente e os processos de maturação (I. C. Schuch Ortiz, Trad.). Porto Alegre: Artmed. (Original publicado em 1979)

\section{Endereço para correspondência}

pbendassolli@gmail.com, lisdrea@gmail.com

Recebido em: 15/12/2009

Aprovado em: 14/07/2010 